Article

\title{
Capital Allocation Methods under Solvency II: A Comparative Analysis
}

\author{
Pablo Durán-Santomil * (D) and Luís Otero-González
}

Citation: Durán-Santomil, P.; Otero-González, L. Capital Allocation

Methods under Solvency II: A Comparative Analysis. Mathematics 2022, 10, 303. https://doi.org/ $10.3390 /$ math 10030303

Academic Editor: Francisco Jareño

Received: 30 December 2021

Accepted: 14 January 2022

Published: 19 January 2022

Publisher's Note: MDPI stays neutral with regard to jurisdictional claims in published maps and institutional affiliations.

Copyright: (C) 2022 by the authors. Licensee MDPI, Basel, Switzerland. This article is an open access article distributed under the terms and conditions of the Creative Commons Attribution (CC BY) license (https:// creativecommons.org/licenses/by/ $4.0 /)$.
Facultad de Ciencias Económicas y Empresariales, Universidade de Santiago de Compostela (USC), Avda. Burgo das Nacións (S/N), 15782 Santiago de Compostela, Spain; luis.otero@usc.es

* Correspondence: pablo.duran@usc.es; Tel.: +34-881811596

\begin{abstract}
The objective of this document is to analyze different methods that an insurer can use to allocate capital to his or her different lines of business or business segments under Solvency II. For this analysis, a review of the main methods developed in the literature is carried out. Many of the proposed methods in the literature can only be implemented with the internal data from the company's loss distributions. In addition to this, in some of the methods that can be applied with external data, the diversifying effect is in essence not assigned to the lines of business (LoBs) that cause it. Therefore, in this paper, we compare the results of the main methods that can be used with public data and propose a simple method of capital allocation for insurance companies, which does not require knowledge of the loss distribution of an $\mathrm{LoB}$, and which allows the diversification benefit to be assigned only to the LoBs that really cause such an effect. A practical example of the differences between the different methods and the one proposed is shown for better understanding.
\end{abstract}

Keywords: Solvency II; capital allocation; lines of business (LoBs); insurance companies; ERM

\section{Introduction}

Capital allocation, also known as capital attribution in insurance companies, has given rise in recent years to a renewed interest due to the current solvency regulatory rules in Europe, namely, Solvency II. In Pillar I, Solvency II requires an insurer to make an assessment of a solvency capital requirement (SCR) by the standard formula or an internal model. The bottom-up aggregation formula proposed by the regulator allows for a diversification effect, but there is no specific allocation formula provided to evaluate the contribution of each risk source on the overall SCR [1]. For Pillar II, an insurance company must implement and use an enterprise risk management (ERM) system [2]. One of many tasks that an insurance company should be able to perform is to allocate capital via its ERM system to all the subdivisions with different objectives [3]. Allocating capital is a good risk management practice because it serves as a risk-reward managing tool. While Pillar I is related to the capital adequacy (the capital needs at the level of the insurance company), the allocation of capital is responsible for distributing the capital of the organization among the subdivisions of a company. Ref. [4] defines capital adequacy as the capital requirement that an insurer must have in order to comply with a specific regulation (such as Solvency II), a rating agency or a benchmark imposed by the company itself. Nevertheless, the said author states that the allocation of an insurance company's capital involves distributing the total resources of a company in business segments (business units, lines, geographical areas and products). The literature understands these segments primarily as lines of business (LoBs) within an insurance company, but from a theoretical point of view, each LoB can have access to all available capital of the company if necessary, such as in the event of an extremely adverse result. Nevertheless, it does not mean that capital is physically shifted across the LoBs [3]. The main objective of a company allocating capital to all the business lines is to reflect the probability that an LoB needs to use the company's capital; therefore, this 
distribution can be used for various tasks, such as making pricing decisions or evaluating the risk-reward performance of each LoB.

Multiple allocation methods have been proposed in the literature; for a review of different methods, readers can consult [4-14]. A recent review and technique comparison can be found at [15]. Ref. [3] states that the multitude of allocation methods proposed in the literature can be bewildering. Although insurers need to allocate capital to effectively manage risk, there is no consensus about the best method to do so. The literature frequently provides a set of various methods, but, in general, there is no practical guidance to implement them. Thus, since a range of capital allocation methods can be used by the same company for different applications, it is essential to understand the differences between diverse approaches. The importance of selecting a capital allocation method for an LoB is that its profitability, premium or business volume can be affected by the allocation process [16]. The objective of this work is to analyze how an insurance company can allocate capital to its LoBs under Solvency II, using the most common allocation models. At the same time, we propose a new capital allocation method. The advantages of the proposed method are the following: it is simple, it can be used without knowing the distribution losses of lines or companies (i.e., internal data), and it is consistent with the standard Solvency II formula.

This paper is structured as follows: Section 2 reviews the literature on capital allocation methods, their uses and their most prominent features; Section 3 specifies the proposed method and the standard formula for the non-life underwriting capital requirement for Solvency II; Section 4 shows the empirical results; the paper ends with conclusions and limitations.

\section{Literature Review}

\subsection{Capital Allocation: Uses}

Capital allocation plays an important role for financial institutions [17] and usually begins with the selection of a risk measure (e.g., variance, value at risk (VaR) or tail value at risk (TVaR)). This is used to calculate the required capital at the company's desired granularity level (such as in LoBs and geographic areas), with the beneficiary initially being treated as independent and isolated. Since the capital amount for the insurer is less than the sum of the independent capital, an allocation rule is chosen to allocate the total capital among its members [14]. Different methods cause different capital allocations, so the decision of which rule or capital allocation model to select is a crucial task for an insurer. We assume that a company has $n$ LoBs, that each one has an initial individual capital requirement of $R C_{i}$ and that the sum of these amounts for the company is $S=\sum_{i=1}^{n} R C_{i}$. We also suppose that the required capital $(R C)$ for a company has already been derived via an economic capital model, which, in the case of Solvency II, can be the standard formula or an internal model. The allocation capital problem is the decomposition of this economic capital into its LoBs, or in other words, finding the non-negative real numbers so that its sum is equal to the aggregate capital [3]. Ref. [5] describes the general process of capital allocation in the following steps:

- $\quad$ Specify a multivariate distribution for the vector of losses for the $n \operatorname{LoBs}\left(L_{1}, \ldots, L_{n}\right)$.

- Select a risk measure R, which allows risk-based capital (RBC) to be calculated. This risk measure could be variance, $\mathrm{VaR}, \mathrm{TVaR}$ or $\mathrm{XTVaR}$, among others.

- Calculate the required capital of the company $(R C)$, as well as the required capital of each LoB (as isolated segments).

- In the case of a positive diversification effect (i.e., when LoBs are not perfectly correlated), apply an allocation rule to determine the capital assigned to each segment.

Several authors are skeptical of, or even opposed to, the need of capital allocation for LoBs (see $[18,19])$, because all the insurer capital is available to assume the losses caused by an LoB if it is necessary [4]. However, the capital allocation must be an important component of an integral risk management system or ERM. Allocation capital for LoBs makes it possible, among other advantages, for an insurer to carry out better pricing decisions, risk management and performance analyses [4]. Nevertheless, there are several authors who 
affirm that capital allocation, rather than being an end in itself, is an intermediate step in the decision-making process for an insurance company. For pricing, capital allocation makes it possible to determine the income generated from the investment when calculating the premiums and to correctly determine the cost of capital. For risk management, allocating capital allows the rate of risk-adjusted return to be determined, which allows decision making to maximize the value of the firm. Finally, capital allocation allows the performance of each LoB (via risk-adjusted performance management (RAPM)) and the company's reward system to be evaluated.

\subsection{Desirable Characteristics of a Capital Allocation Method}

There are multiple desirable characteristics of a method for allocating capital, although there is no existing one which has all of them. Some of the features are as follows:

- it must be accepted within the organization, given that different methods or rules involve different assignments;

- the sums of capital allocated to the LoBs must be equal to the total capital of the insurer;

- it must not provide negative capital allocations to any LoB;

- the magnitude of diversification benefit should be able to be identified.

Important questions for an insurer to ponder are whether one method is better for all purposes, or even whether the method(s) need(s) to be stable over time. An important feature for insurers is that the capital rule should be coherent. An allocation method is coherent if it meets three necessary axioms [20], as follows:

- No undercut: Capital allocation to an LoB should not be greater than its capital requirement if it is an independent unit. This property ensures that if a new LoB is added to a company, the total insurer capital will not increase more than the new risk added by the new LoB.

- Symmetry: If the risk of two LoBs is the same, then the capital allocation must be the same for each LoB. This axiom ensures that the capital allocation depends exclusively on the risk contributions of each LoB to the company.

- Riskless allocation: The capital allocated to a risk-free LoB must be zero.

A non-negative coherent allocation satisfies the condition that the proportion of capital allocated to each LoB is greater than or equal to zero.

\subsection{Capital Allocation: Methods}

The literature proposes a set of methods to allocate capital to LoBs; although, as we have already mentioned, there is no consensus about which method is best. Ref. [10] classifies the methods of capital allocation into simple methods (naïve methods), based on risk theory (e.g., covariance, conditional $\mathrm{VaR}$ and Euler), economic theories or valuation of companies (such as the Myers and Read method) and game theory models (i.e., Shapley, among others). (The authors, at the request of the CAS (Casualty Actuarial Society) for "The Risk Premium Project (RPP) Update-RPP II Report", performed a review of the actuarial and financial literature, showing the methods of capital allocation published to this date. The revision of methods is not exhaustive and leaves out important references, such as the Ruhm-Mango-Kreps method [the RMK algorithm] [21,22]) Next, we will describe several of the methods used in the literature that will be employed later in the empirical part of this paper.

$R C$ is the capital requirement of the insurer and $R C_{i}$ is the capital requirement of each $\mathrm{LoB}$ as an isolated segment. If there is a diversification benefit, the sum of the capital of the individual LoBs will be lower than the global capital requirement, so $\sum_{i=1}^{n} R C_{i}-R C \geq 0$. We denote with $R\left(L_{i} ; L\right)$ the contribution of the LoB $i$ to the global risk $R(L)$. The capital allocation methods are said to perform a full allocation if all the capital of the company is allocated to the different business lines, i.e., $\sum_{i=1}^{n} R\left(L_{i} ; L\right)=R(L)$. There are methods that do not perform a full allocation, i.e., not all capital is distributed among all the LoBs, 
meaning that a part of the capital is available for all. Next, we review the main full allocation methods that can be used in Solvency II, without having knowledge of the loss distribution of each LoB and company (such as the internal data of the company).

Among the simple methods, Ref. [10] cites the proportional allocation method, also known in the literature as "linear marginal contributions" or the "First in" method ([6,23] refer to this method as the activity-based method). Linear, or proportional, allocation is the simplest approach and assumes that the total capital of an insurance company (including the diversification effect) is allocated proportionally to each LoB. This approach assigns the diversification benefit to LoBs in proportion to each individual capital requirement [5]. Therefore, it does not penalize LoBs that have a high correlation with the rest causing fewer advantages from diversification. Similarly, it does not reward LoBs that have seen the benefits of diversification increase, because they are poorly correlated with the rest. The steps to apply this method are to calculate the necessary capital for the company and for each LoB in isolation (as if they were the only LoBs in the company). The capital allocated to the $\operatorname{LoB} i$, called $R\left(L_{i} ; L\right)$, can be calculated as follows:

$$
R\left(L_{i} ; L\right)=\frac{R\left(L_{i}\right)}{\sum_{j=1}^{n} R\left(L_{j}\right)} R(L)
$$

where $R\left(L_{i}\right)$ is the capital amount calculated for LoB $i$ in isolation, $\sum_{j=1}^{n} R\left(L_{j}\right)$ is the sum of the capital for all LoBs without considering the diversification benefit, and finally, $R(L)$ is the capital amount for the whole company, considering the diversification benefit.

Another simple method, according to the [10] classification, is known as "discrete marginal contributions" or the "Last in" method (see [8]). Discrete marginal contributions are calculated by determining the amounts of marginal risk that an LoB contributes to the total portfolio of risk. Insurer capital is calculated by excluding LoBs one by one. For example, to calculate the discrete marginal contribution of LoB 1 to affirm the capital accumulated by three LoBs (1,2 and 3), we must calculate the capital of the company that needs to include business-only lines 2 and 3 (capital of 23, in the nomenclature that we will use). This calculated capital has to be subtracted from the total portfolio capital to reach the amount of marginal risk that the LoB 1 contributes to the total portfolio (capital of 123-capital of 23). Subsequently, we must do the same for business line 2 (capital of 123-capital of 13) and line 3 (capital of 123-capital of 12).

Discrete marginal contributions are an approximative approach to the "continuous marginal contributions approach," or the Euler method. We employ the "discrete marginal contributions scale" [24], so that the sum of contributions equals the total capital requirement of the insurer.

The method of continuous marginal contributions, or the Euler method, calculates the derivative of the total risk to the insurance company with respect to the risk of each individual LoB, so it is often referred to as the gradient or marginal contribution method [7]. It measures the sensitivity of the total capital requirement to a very small additional exposure of a LoB. Once the derivatives for each LoB are calculated, they are multiplied by the risk measures of each LoB to give the continuous marginal contribution. If $\rho(X)$ is a risk measure and assuming that it is a 1-degree homogeneous and continuously differentiable function, the risk contributions $\left[\rho\left(X_{1} \mid X\right), \ldots, \rho\left(X_{q} \mid X\right)\right]$ are uniquely determined as follows:

$$
\rho_{\text {Euler }}(X)=\rho\left(X_{i}\right) \frac{\delta \rho(X)}{\delta \rho\left(X_{i}\right)} \text { for } i=1, \ldots, n
$$

Ref. [1] provides closed formulas for capital allocation based on the Euler allocation principle in the Solvency II framework.

Other types of methods for capital allocation are those that derive from game theory, which studies situations where players adopt various strategies to best achieve their individual targets and is a widely used approach to decision making in moments of conflict. One example of these allocating capital is how to share the diversification benefit between each 
LoB due to the fact that it benefits from being part of a larger diversified company, while it also renounces some of the benefit for being part of it. Games with a coalition structure $(N, c)$ consist of a finite set $N$ of $n$ players and a function $c$ that associates a real number $c(S)$ to each subset, $S$ of $N$ (called a coalition). The allocation of capital between all players (the LoBs) is formalized by the concept of value. A value is a function, $\Phi: G \rightarrow R^{n}$, that maps each game $(N, c)$ into a unique allocation. The Shapley value for the game $(N, c)$ is defined as a function that assigns to each player $i$, as follows:

$$
\text { Shapley }_{i}=\sum_{S \in C_{i}} \frac{(s-1) !(n-s) !}{n !}(c(s)-c(s \backslash\{i\})), i \in N
$$

where $s=\operatorname{card}(S), N$ is the number of players and $C_{i}$ represents all coalitions of $N$ that contain $i$. Shapley's method considers the role that each LoB plays in all possible combinations (called coalitions) of LoBs, and their contribution to the capital required for each combination. This requires the evaluation of $c$ for each of the possible $2^{n}$ coalitions, leading to a number of possible combinations, $2^{n}-1$, to be exact, to analyze. As a result, the marginal contribution of each business unit to the whole gives an approximation, which makes it possible for capital to be allocated between all the lines in accordance with the marginal contribution of each of them.

\section{Solvency II: Standard Formula for Non-Life Underwriting Risk and Proposed Criterion for Capital Allocation}

\subsection{Standard Formula for Non-Life Underwriting Risk}

The standard formula of Solvency II has been calibrated based on the different quantitative impact studies, the QIS, and is subject to revisions. The Solvency II standard model is based on a modular structure where the main modules identified in the risk map are operational, market, underwriting risk (life, non-life and health), counterparty default risk and intangible assets. For the calculation of capital, the risks measured via the VaR at $99.5 \%$ confidence interval are calculated within each submodule [25]. Once the capital charges within each submodule have been calculated, these are added taking account of the dependence between risks. Dependences among the risks are measured using correlation matrices (see, for example, [26]). Therefore, the capital requirements are not additive and there is a diversification benefit.

Solvency II defines the non-life underwriting risk as the loss or adverse modification in value of non-life insurance due to the inadequacy of the pricing or provisions hypothesis. To measure the non-life insurance risk, an internal model, the general formula or specific parameters are allowed [27]. Solvency II rules allow for the possibility of replacing predefined parameters with specific company ones that are more appropriate to their own risk profile; in certain cases, simplifications of the standard formula, based on the nature, scale or volume and complexity of risks are used instead. The specific parameters are an intermediate model between the standard formula and the internal model. The formulation of the standard model is used for the internal model, but parameter calibration is carried out based on the historical data of the company itself, both with regard to premiums and reserves. Within this module, the following submodules are distinguished: premiums and reserves, catastrophic (CAT) and lapse. For risk aggregation, the following formula is used:

$$
S C R_{\text {non-life }}=\sqrt{\sum_{i . j} \operatorname{CorrNonlife}_{(i, j)} \cdot S C R_{i} \cdot S C R_{j}}
$$

where $S C R_{i}$ and $S C R_{j}$ are the solvency capital requirements, premium and reserve risk, CAT risk and lapse risk are the submodules and CorrNonlife $e_{(i, j)}$ is the correlation matrix (Table 1). 
Table 1. Non-life risk correlation matrix under Solvency II regulation.

\begin{tabular}{cccc}
\hline Risk & Premium and Reserve Risk & CAT Risk & Lapse Risk \\
\hline Premium and reserve risk & $100 \%$ & $25 \%$ & 0 \\
CAT risk & $25 \%$ & $100 \%$ & 0 \\
Lapse risk & 0 & 0 & $100 \%$ \\
\hline
\end{tabular}

This table shows the risk correlation between the modules of premium and reserve risk, CAT risk and lapse risk. Source: Delegated Regulation (EU) 2015/35.

The capital charge for premium and reserve risk is calculated as three times the combined standard deviation, $\left(\sigma_{\text {non-life }}\right)$, multiplied by the volume measure, $\left(V_{\text {non-life }}\right)$, as follows:

$$
S C R_{\text {premium_reserves }}=3 \cdot \sigma_{\text {non-life }} \cdot V_{\text {non-life }}
$$

The Volume measure, $\left(V_{\text {non-life }}\right)$, is obtained from the sum of the volume measures of the different segments for premium and reserve risks, $\left(V_{(\text {premium }, s)}\right.$ and $\left.V_{(\text {reserves }, s)}\right)$, taking into account the geographical diversification factor of the segment $\mathrm{s}\left(D I V_{s}\right)$, which occurs when a company operates in different geographical areas. The formula for calculating the volume of each segment is given by the following:

$$
V_{s}=\left(V_{(\text {premiums }, s)}+V_{(\text {reserves }, s)}\right) \cdot\left(0.75+0.25 \cdot D I V_{s}\right)
$$

The standard deviation measure for each segment $\left(\sigma_{s}\right)$ is obtained from the deviations for the risk of both premiums $\left(\sigma_{(\text {premiums }, s)}\right)$ and reserves $\left(\sigma_{(\text {reserves,s })}\right)$ for each segment(s) using the following formula:

$$
\sigma_{s}=\frac{\sqrt{\sigma_{(\text {premiums }, s)}^{2} \cdot V_{(\text {premiums }, s)}^{2}+\sigma_{(\text {premiums }, s)} \cdot V_{(\text {premiums }, s} \cdot \sigma_{(\text {reserves }, s)} \cdot V_{(\text {reserves }, s)}+\sigma_{(\text {reserves }, s)}^{2} \cdot V_{(\text {reserves }, s)}^{2}}}{V_{(\text {premiums }, s)}+V_{(\text {reserves }, s)}}
$$

The standard deviation data of the premiums and reserves for each segment $\left(\sigma_{(\text {premiums,s })}\right.$ and $\left.\sigma_{(\text {reserves,s) }}\right)$ is provided in Delegated Regulation 2015/35, supplementing Directive 2009/138/EC of the European Parliament and of the Council (Solvency II Directive). For example, for segment $1, \sigma_{(\text {premiums s) }}$, is equal to $10 \%$ and $\sigma_{(\text {reserves,s) }}$ is equal to $9 \%$. There are 12 segments (s), which correspond with 21 LoBs defined in the Solvency II regulations. This is due to LoBs of proportional reinsurance obligations being included in the same segment as direct insurance, with the exception of the last three segments of non-proportional reinsurance that correspond with LoBs themselves. The matrix for the segments is shown in Table 2. The model breaks down non-life business into 12 segments and the current correlation matrix has coefficients that vary between 0.25 and 0.5 for the segments.

Table 2. Correlation matrix between segments (CorrNonlife $(i, j))$.

\begin{tabular}{ccccccccccccc}
\hline $\boldsymbol{s}$ & $\mathbf{1}$ & $\mathbf{2}$ & $\mathbf{3}$ & $\mathbf{4}$ & $\mathbf{5}$ & $\mathbf{6}$ & $\mathbf{7}$ & $\mathbf{8}$ & $\mathbf{9}$ & $\mathbf{1 0}$ & $\mathbf{1 1}$ & $\mathbf{1 2}$ \\
\hline 1 & $100 \%$ & $50 \%$ & $50 \%$ & $25 \%$ & $50 \%$ & $25 \%$ & $50 \%$ & $25 \%$ & $50 \%$ & $25 \%$ & $25 \%$ & $25 \%$ \\
2 & $50 \%$ & $100 \%$ & $25 \%$ & $25 \%$ & $25 \%$ & $25 \%$ & $50 \%$ & $50 \%$ & $50 \%$ & $25 \%$ & $25 \%$ & $25 \%$ \\
3 & $50 \%$ & $25 \%$ & $100 \%$ & $25 \%$ & $25 \%$ & $25 \%$ & $25 \%$ & $50 \%$ & $50 \%$ & $25 \%$ & $25 \%$ & $50 \%$ \\
4 & $25 \%$ & $25 \%$ & $25 \%$ & $100 \%$ & $25 \%$ & $25 \%$ & $25 \%$ & $50 \%$ & $50 \%$ & $50 \%$ & $25 \%$ & $50 \%$ \\
5 & $50 \%$ & $25 \%$ & $25 \%$ & $25 \%$ & $100 \%$ & $50 \%$ & $50 \%$ & $25 \%$ & $50 \%$ & $25 \%$ & $50 \%$ & $25 \%$ \\
6 & $25 \%$ & $25 \%$ & $25 \%$ & $25 \%$ & $50 \%$ & $100 \%$ & $50 \%$ & $25 \%$ & $50 \%$ & $25 \%$ & $50 \%$ & $25 \%$ \\
7 & $50 \%$ & $50 \%$ & $25 \%$ & $25 \%$ & $50 \%$ & $50 \%$ & $100 \%$ & $25 \%$ & $50 \%$ & $25 \%$ & $50 \%$ & $25 \%$ \\
8 & $25 \%$ & $50 \%$ & $50 \%$ & $50 \%$ & $25 \%$ & $25 \%$ & $25 \%$ & $100 \%$ & $50 \%$ & $50 \%$ & $25 \%$ & $25 \%$ \\
9 & $50 \%$ & $50 \%$ & $50 \%$ & $50 \%$ & $50 \%$ & $50 \%$ & $50 \%$ & $50 \%$ & $100 \%$ & $25 \%$ & $25 \%$ & $50 \%$ \\
10 & $25 \%$ & $25 \%$ & $25 \%$ & $50 \%$ & $25 \%$ & $25 \%$ & $25 \%$ & $50 \%$ & $25 \%$ & $100 \%$ & $25 \%$ & $25 \%$ \\
11 & $25 \%$ & $25 \%$ & $25 \%$ & $25 \%$ & $50 \%$ & $50 \%$ & $50 \%$ & $25 \%$ & $25 \%$ & $25 \%$ & $100 \%$ & $25 \%$ \\
12 & $25 \%$ & $25 \%$ & $50 \%$ & $50 \%$ & $25 \%$ & $25 \%$ & $25 \%$ & $25 \%$ & $50 \%$ & $25 \%$ & $25 \%$ & $100 \%$ \\
\hline
\end{tabular}

This table shows the risk correlation between the 12 business segments (s), which correspond with the 21 LoBs for non-life insurance specified under Solvency II regulation. Source: Delegated Regulation (EU) 2015/35. 
In addition to the premium and reserve risk submodule, in order to compute the non-life SCR, the SCR for lapse risk and CAT risk must be taken into account. The risk of lapse risk is less important in non-life insurance than in life insurance, because in non-life insurance long-term contracts are less frequent.

\subsection{Proposed Method for Capital Allocation Using the Standard Formula}

We propose a method to allocate capital among different segments under the Solvency II standard formula. Unlike previous methods, we consider it more appropriate for capital diversification to be assigned to the segments that have little correlation with others. Consequently, first of all, we calculate the diversification benefit for the different pairs of segments $i, j$. This diversification benefit will be exclusively allocated to segments $i, j$ and, unlike other methods, such as the proportional allocation method, it does not benefit other segments. In addition, the method must ensure that the diversification benefit is fully distributed among the segments. The steps to calculate the capital allocation in the case of an insurer with three LoBs or segments (1, 2 and 3) are the following:

- To calculate the diversification benefit between segments 1 and 2, the global capital of the company minus the necessary capital is calculated. We define necessary capital as the capital in the case that the matrix of correlations between risks is formed by all 1 segments (perfectly correlated segments) except for the correlation coefficient between segments 1 and 2, which is the one defined in the Solvency II standard formula matrix.

- To calculate the diversification benefit between segments 1 and 3, the global capital of the company minus the necessary capital is calculated. We define necessary capital as the capital in the case that the matrix of correlations between risks is formed by all 1 segments (perfectly correlated segments), except for the correlation coefficient between segments 1 and 3, which is the one defined in the Solvency II standard formula matrix (see Table 2).

- $\quad$ Similarly, we compute the diversification benefit from segments 2 and 3 .

- Since the sum of the calculated diversification benefits of the segments is not the same as the original diversification benefit, it is necessary to rescale the calculation to ensure that all capital is distributed between segments.

- Once the sum of the diversification benefits is rescaled, the diversification benefit for the pairs of segments $i, j$ is reallocated to the relevant segments. We propose two options: the 1st is to make reallocation in proportion to the original capital charges (option 1); the 2nd is to allocate the diversification benefit equally between the relevant segments (option 2). These two options yield results which should be considered as setting the bounds, or limits, of a good allocation method.

The proposed method guarantees that if the linear correlation coefficient of one segment with respect to all others is 1 , the final capital allocated to the segment will not see any advantage of diversification benefit. Similarly, in the real case of the correlation matrix that is currently used in the Solvency II standard formula, the diversification benefit is distributed to a greater extent to the segments that have low correlation coefficients between them, than those which have more correlations. In addition, as we will see in the practical application of the proposed method (empirical results section), desirable characteristics of the capital allocation method set in Section 2.2 are met.

\section{Results}

In this section, we compute the capital requirement for the premium and reserve risk $\left(S C R_{\text {premium_reserves }}\right)$ among the different segments of a hypothetical insurer. The methods and the proposed criteria can be used to allocate other capital requirements (such as the market) or the global capital requirement (SCR)). This hypothetical insurer operates in the 12 Solvency II segments, and its data comprises the sum of all Spanish insurance companies. This data is not publicly accessible, so we would like to thank ICEA for their collaboration. ICEA is a non-profit Spanish association of insurance entities whose objective is to study and investigate matters related to insurance. Currently, it has more than 200 
member entities, representing more than $95 \%$ of the sector's premiums in Spain. The data provided is aggregated to avoid the identification of insurers. Spain in one of the EU's largest insurance markets). Table 3 shows the volume of premiums and of reserves for the 12 Solvency II segments in the case of the hypothetical insurer.

Table 3. Premium and reserve volume data.

\begin{tabular}{ccc}
\hline Segment $(s)$ & $\begin{array}{c}\text { Premium Volume } \\
V_{(\text {premiums }, s)}\end{array}$ & $\begin{array}{c}\text { Reserve Volume } \\
V_{(\text {reserves }, s)}\end{array}$ \\
\hline 1 & $5,401,178,414$ & $3,908,605,158$ \\
2 & $4,805,553,844$ & $682,191,430$ \\
3 & $303,821,805$ & $204,818,835$ \\
4 & $6,770,389,666$ & $1,687,261,978$ \\
5 & $1,000,232,241$ & $2,012,019,532$ \\
6 & $181,617,487$ & $94,428,343$ \\
7 & $197,431,398$ & $69,028,175$ \\
8 & $736,820,112$ & $84,694,892$ \\
9 & $366,955,649$ & $38,710,152$ \\
10 & 352,121 & $1,807,426$ \\
11 & 500 & 85,892 \\
12 & 872,016 & $1,629,329$ \\
\hline
\end{tabular}

This table shows the premium and reserve volume data for a hypothetical insurer which represents the entire Spanish insurance market. Source: own calculations based on information provided by insurers to ICEA.

Given the standard formulas, the measures for the volume and risk of premiums and reserves for each of the twelve segments are calculated. According to the data reported by the companies, they all operate in the same geographical area $\left(D I V_{s}\right.$ is equal to 1$)$. The standard formula calculates the aggregate risk of premiums and reserves via the aggregate volatility of the portfolio (5.9\%) and the measure of aggregate volume (EUR 28,550,506,397) multiplied by 3 . Since the capital needed for the total number of companies in the Spanish market is EUR 5,057,462,439 (see Table 4) and the sum of the individual capital for the different segments is EUR 7,181,702,391, a capital allocation method must be applied to allocate the diversification benefit of EUR 2,124,239,953.

Table 4. Required capital for the premium and reserve risk for the Spanish insurance sector (segment and total sector).

\begin{tabular}{cccc}
\hline Segment $(s)$ & $V_{s}$ & $\sigma_{s}$ & $\begin{array}{c}\text { Required Capital } \\
\text { SCR }_{\text {premium }} \text { reserves }, s\end{array}$ \\
\hline 1 & $9,309,783,572$ & $8.4 \%$ & $2,334,362,865$ \\
2 & $5,487,745,274$ & $7.6 \%$ & $1,243,307,498$ \\
3 & $508,640,640$ & $11.8 \%$ & $180,282,184$ \\
4 & $8,457,651,645$ & $7.6 \%$ & $1,928,466,239$ \\
5 & $3,012,251,773$ & $10.5 \%$ & $946,712,235$ \\
6 & $276,045,830$ & $12.5 \%$ & $103,397,442$ \\
7 & $266,459,573$ & $7.3 \%$ & $58,024,237$ \\
8 & $821,515,004$ & $9.3 \%$ & $228,625,562$ \\
9 & $405,665,801$ & $12.8 \%$ & $156,027,709$ \\
10 & $2,159,547$ & $18.3 \%$ & $1,184,501$ \\
11 & 86,392 & $19.9 \%$ & 51,663 \\
12 & $2,501,346$ & $16.8 \%$ & $1,260,256$ \\
\hline \multirow{2}{*}{ Total sector (TS) } & $V_{\text {non-life }}$ & $\sigma_{\text {non-life }}$ & Required capital \\
TS & $28,550,506,397$ & $5.90 \%$ & $S C R_{\text {premium }}$ \\
\hline reserves
\end{tabular}

This table shows the volume and risk of premiums and reserves, $\left(V_{s}\right.$ and $\left.V_{\text {non-life }}\right)$, their volatility, $\left(\sigma_{S}\right.$ and $\left.\sigma_{\text {non-life }}\right)$, and the required capital for the premium and reserve risks, $\left(S C R_{\text {premium }}\right.$ reserves $)$ for a hypothetical insurer which represents the entire Spanish insurance market. Data is show for each the 12 business segments (s) and for the total sector (TS). Note: calculations use Equation (5) and the correlation matrix of Table 2. Source: own calculations based on information provided by insurers to ICEA. 


\subsection{Basecase}

The results from the allocation methods are shown in Table 5. The proportional method simply assigns the diversification benefit in the same proportions to the 12 segments. Thus, for example, the capital allocated to segment 1 would be the capital needed for this segment in isolation multiplied by the insurer's capital and divided by the arithmetic sum of the necessary capital of the company, i.e., (EUR 2, 334, 362, 865.EUR 5, 057, 462, 439)/ EUR 7,181, 702, $391=$ EUR 1,643, 893, 309.

Table 5. Capital allocated to each segment under different methods.

\begin{tabular}{cccccccc}
\hline$s$ & Proportional & Last in & Incremental & Euler & Shapley & $\begin{array}{c}\text { Proposed } \\
\text { (Option 1) }\end{array}$ & $\begin{array}{c}\text { Proposed } \\
\text { (Option 2) }\end{array}$ \\
\hline 1 & $1,643,893,309$ & $1,940,372,388$ & $1,934,717,247$ & $1,935,025,197$ & $1,858,568,047$ & $1,587,571,612$ & $1,761,116,019$ \\
2 & $875,555,771$ & $861,801,362$ & $841,255,583$ & $841,292,465$ & $853,818,528$ & $887,392,395$ & $862,664,420$ \\
3 & $126,957,416$ & $105,151,574$ & $92,991,298$ & $93,063,240$ & $97,108,587$ & $162,436,607$ & $113,928,013$ \\
4 & $1,358,054,823$ & $1,165,911,833$ & $1,273,786,946$ & $1,273,025,875$ & $1,306,360,903$ & $1,216,851,590$ & $1,319,050,628$ \\
5 & $666,688,942$ & $617,634,224$ & $593,029,874$ & $593,101,276$ & $613,310,928$ & $699,470,643$ & $638,220,626$ \\
6 & $72,814,028$ & $50,282,490$ & $44,188,401$ & $44,225,150$ & $49,271,630$ & $96,406,914$ & $61,640,387$ \\
7 & $40,861,537$ & $40,135,308$ & $34,785,892$ & $34,819,489$ & $34,199,832$ & $55,833,621$ & $38,675,140$ \\
8 & $161,001,546$ & $144,918,699$ & $128,477,634$ & $128,574,266$ & $134,254,995$ & $203,610,275$ & $148,724,303$ \\
9 & $109,877,050$ & $129,913,035$ & $113,073,842$ & $113,178,574$ & $109,409,541$ & $145,395,482$ & $111,917,169$ \\
10 & 834,143 & 634,307 & 546,454 & 547,014 & 545,377 & $1,183,006$ & 723,151 \\
11 & 36,382 & 24,554 & 21,149 & 21,171 & 21,993 & 51,660 & 30,449 \\
12 & 887,491 & 682,664 & 588,119 & 588,721 & 592,078 & $1,258,634$ & 772,132 \\
\hline
\end{tabular}

This table shows the capital allocated to each of the 12 business segments (s) under different methods (proportional, last in, incremental, Euler, Shapley and the proposed method). Source: own calculations.

The "last in" allocation method is based on the discrete marginal contribution of each segment to the insurer capital. Hence, the VaRs of the portfolios are calculated at 99.5\% confidence. These exclude the risk of each segment so that the discrete marginal contribution of segment 1 is the risk of a multi-risk portfolio for the rest of the segments (the whole company except segment 1) minus the risk of the joint portfolio (the capital requirement for the whole company, i.e., the 12 segments). For example, given that total capital is EUR 5,557,462,439, the marginal contribution of segment 1 to the firm is EUR 5, 057, 462, 439 - EUR 3, 384, 455, 909 = EUR 1, 673, 006, 530, which assumes that EUR $3,384,455,909$ is the necessary capital for the portfolio of segments $2-12$. The sum of the discrete marginal contributions of the 12 segments amounts to EUR 4,360,589,615. To calculate the capital allocated to segment 1, its marginal contribution is simply scaled in relation to the sum of marginal contributions, that is, the capital finally allocated is EUR 1,940,372,388, which is obtained as EUR 1,673,006, 530.EUR 5, 057, 462, 439/EUR 4, 360, 589, 615.

The incremental method analyzes the effect that occurs in the risk portfolio when faced with small variations in risks. Thus, if we increase the risk of segment 1 by $1 \%$, the resulting capital for the company would be EUR 5,076,829,482; similarly, the result would be EUR 5,065,883,635 in the case of increasing the risk of segment 2 by $1 \%$, etc. The above implies that the effect in the company's capital of increasing the risk of segment 1 by 1\% is EUR 19,367,043, computed as EUR 5, 076, 829, 482 - EUR 5, 057, 462, 439. The sum of the capital increase resulting from the increase in all the 12 segments by $1 \%$ is EUR 50,626,568. Finally, the capital allocated to segment 1 is EUR 1,940,372,388 (EUR 5, 057, 462, 439.EUR 19, 367, 043/EUR 50, 626, 568). 
The Euler method achieves similar results to the discrete incremental method, since this is based on derivative or infinitesimal change. To apply the Euler method to the capital of segment 1 , we simply multiply the capital of the segment in isolation (EUR $2,334,362,865)$ by the sum of the product of the isolated capitals of the 12 segments and the first column of the correlation coefficient matrix of Solvency II between segments (correlation coefficients of segment 1 with respect to segments 1-13). Then, we divide the result by the insurer capital (EUR 5,057,462,439). To serve as an example, the capital of segment 1 would be EUR 1,935,025,197 based on the following formula: $2,334,362,865[2,334,362,865 \cdot 1+1,243,307,498 \cdot 0.5+180,282,184 \cdot 0.5+1,928,466,239 \cdot 0.25+$ $946,712,235 \cdot 0.5+103,397,442 \cdot 0.25+58,024,237 \cdot 0.5+228,625,562 \cdot 0.25+156,027,709 \cdot 0.5+$ $1,184,501 \cdot 0.25+51,663 \cdot 0.25+1,260,256 \cdot 0.25] / 5,057,462,439$.

Shapley's method for this company, with 12 segments, leads to a set of 4.096 possible coalitions. The results have been calculated using the GameTheoryAllocation package of $\mathrm{R}$ [28].

Last of all, we will consider the proposed method. To apply this approach we need to calculate the difference between (a) the capital resulting from the sum of the capital of each segment in the event that the correlation matrix is composed of segments 1 (perfectly positively correlated risks) and (b) the capital resulting from the sum of capital assuming that the correlation matrix between risks is all segments 1, except for the correlation coefficient between 2 segments, which is defined by the correlation coefficient of the standard formula of Solvency II. Thus, the difference between (a) and (b) is the diversification benefit derived from that pair of segments. These benefits can be shared between the segments based on their value (option 1) or evenly among them (option 2). These are the limits for a true allocation method.

Table 6 shows the percentage of capital for the total sector assigned to each segment. Segment 1, which corresponds with line of business 4 , motor vehicle liability insurance and 16, proportional motor vehicle liability reinsurance-as defined in Annex I to Delegated Regulation (EU) 2015/35-is the segment to which the highest percentage of capital is allocated under the different methods employed, due to its high volume (premium and reserve). Table 7 shows the percentage of allocated or final capital for a segment with respect to their initial capital (the capital that it would have had in isolation). For example, the reader can see how the proportional method assigns the same percentage $(70.42 \%)$ of capital to all segments while other methods set different percentages.

Table 6. Capital allocated (percentage with respect to the total) under different methods.

\begin{tabular}{|c|c|c|c|c|c|c|c|}
\hline$s$ & Proportional & Last in & Incremental & Euler & Shapley & $\begin{array}{c}\text { Proposed } \\
\text { (Option 1) }\end{array}$ & $\begin{array}{r}\text { Proposed } \\
\text { (Option 2) }\end{array}$ \\
\hline 1 & $32.5 \%$ & $38.4 \%$ & $38.3 \%$ & $38.3 \%$ & $36.7 \%$ & $31.4 \%$ & $34.8 \%$ \\
\hline 2 & $17.3 \%$ & $17.0 \%$ & $16.6 \%$ & $16.6 \%$ & $16.9 \%$ & $17.5 \%$ & $17.1 \%$ \\
\hline 3 & $2.5 \%$ & $2.1 \%$ & $1.8 \%$ & $1.8 \%$ & $1.9 \%$ & $3.2 \%$ & $2.3 \%$ \\
\hline 4 & $26.9 \%$ & $23.1 \%$ & $25.2 \%$ & $25.2 \%$ & $25.8 \%$ & $24.1 \%$ & $26.1 \%$ \\
\hline 5 & $13.2 \%$ & $12.2 \%$ & $11.7 \%$ & $11.7 \%$ & $12.1 \%$ & $13.8 \%$ & $12.6 \%$ \\
\hline 6 & $1.4 \%$ & $1.0 \%$ & $0.9 \%$ & $0.9 \%$ & $1.0 \%$ & $1.9 \%$ & $1.2 \%$ \\
\hline 7 & $0.8 \%$ & $0.8 \%$ & $0.7 \%$ & $0.7 \%$ & $0.7 \%$ & $1.1 \%$ & $0.8 \%$ \\
\hline 8 & $3.2 \%$ & $2.9 \%$ & $2.5 \%$ & $2.5 \%$ & $2.7 \%$ & $4.0 \%$ & $2.9 \%$ \\
\hline 9 & $2.2 \%$ & $2.6 \%$ & $2.2 \%$ & $2.2 \%$ & $2.2 \%$ & $2.9 \%$ & $2.2 \%$ \\
\hline 10 & $0.0 \%$ & $0.0 \%$ & $0.0 \%$ & $0.0 \%$ & $0.0 \%$ & $0.0 \%$ & $0.0 \%$ \\
\hline 11 & $0.0 \%$ & $0.0 \%$ & $0.0 \%$ & $0.0 \%$ & $0.0 \%$ & $0.0 \%$ & $0.0 \%$ \\
\hline 12 & $0.0 \%$ & $0.0 \%$ & $0.0 \%$ & $0.0 \%$ & $0.0 \%$ & $0.0 \%$ & $0.0 \%$ \\
\hline
\end{tabular}

This table shows the percentage with respect to the total capital allocated to each of the 12 business segments ( $s$ ) under different methods (proportional, last in, incremental, Euler, Shapley and the proposed method). Source: own calculations. 
Table 7. Percentage of final capital allocated to each segment (with respect to its initial required capital).

\begin{tabular}{|c|c|c|c|c|c|c|c|}
\hline$s$ & Proportional & Last in & Incremental & Euler & Shapley & $\begin{array}{c}\text { Proposed } \\
\text { (Option 1) }\end{array}$ & $\begin{array}{c}\text { Proposed } \\
\text { (Option 2) }\end{array}$ \\
\hline 1 & $70.4 \%$ & $83.1 \%$ & $82.9 \%$ & $82.9 \%$ & $79.6 \%$ & $68.0 \%$ & $75.4 \%$ \\
\hline 2 & $70.4 \%$ & $69.3 \%$ & $67.7 \%$ & $67.7 \%$ & $68.7 \%$ & $71.4 \%$ & $69.4 \%$ \\
\hline 3 & $70.4 \%$ & $58.3 \%$ & $51.6 \%$ & $51.6 \%$ & $53.9 \%$ & $90.1 \%$ & $63.2 \%$ \\
\hline 4 & $70.4 \%$ & $60.5 \%$ & $66.1 \%$ & $66.0 \%$ & $67.7 \%$ & $63.1 \%$ & $68.4 \%$ \\
\hline 5 & $70.4 \%$ & $65.2 \%$ & $62.6 \%$ & $62.6 \%$ & $64.8 \%$ & $73.9 \%$ & $67.4 \%$ \\
\hline 6 & $70.4 \%$ & $48.6 \%$ & $42.7 \%$ & $42.8 \%$ & $47.7 \%$ & $93.2 \%$ & $59.6 \%$ \\
\hline 7 & $70.4 \%$ & $69.2 \%$ & $60.0 \%$ & $60.0 \%$ & $58.9 \%$ & $96.2 \%$ & $66.7 \%$ \\
\hline 8 & $70.4 \%$ & $63.4 \%$ & $56.2 \%$ & $56.2 \%$ & $58.7 \%$ & $89.1 \%$ & $65.1 \%$ \\
\hline 9 & $70.4 \%$ & $83.3 \%$ & $72.5 \%$ & $72.5 \%$ & $70.1 \%$ & $93.2 \%$ & $71.7 \%$ \\
\hline 10 & $70.4 \%$ & $53.6 \%$ & $46.1 \%$ & $46.2 \%$ & $46.0 \%$ & $99.9 \%$ & $61.1 \%$ \\
\hline 11 & $70.4 \%$ & $47.5 \%$ & $40.9 \%$ & $41.0 \%$ & $42.6 \%$ & $100.0 \%$ & $58.9 \%$ \\
\hline 12 & $70.4 \%$ & $54.2 \%$ & $46.7 \%$ & $46.7 \%$ & $47.0 \%$ & $99.9 \%$ & $61.3 \%$ \\
\hline
\end{tabular}

This table shows the percentage of final capital allocated to each of the 12 business segments $(s)$ with respect to its initial required capital under different methods (proportional, last in, incremental, Euler, Shapley and the proposed method). Source: own calculations.

\subsection{Sensitive Analysis}

In this subsection, we will describe the findings obtained by the different models that would result from the application of other matrices of correlation between risks, a scenario that could happen in the future since the current standard formula is subject to revision. It would be interesting to analyze the strengths and weaknesses of the proposed methods. Firstly, and given that the correlation matrix currently set in the standard non-life insurance model has coefficients of 0.5 and 0.25 between segments, it would be useful to analyze a case in which the matrix for a company were symmetric; for which we could assume that the pairs of correlations between the segments were 0.5 . The second sensitive analysis may assume that the correlation coefficients between segments were 1 between some segments, and 0 between others. This case would be an extreme example that would be unlikely to occur, but it would allow us to see the advantages and disadvantages of the analyzed methods. Finally, we could vary the number of company segments (from 2 to 11 segments).

For sensitive analysis, we have observed that the proportional method does not vary its percentage capital charges to the segments with respect to the base case, because its formula is not sensitive to the correlation coefficients between the segments. The "last in" method is sensitive to correlations, but with undesirable effects on capital allocation. In some cases, the capital of a segment is higher than in the case of an isolated segment, that is, in an insurer formed only by this segment. This undesirable characteristic also occurs for the incremental method and Shapley. In general, the Euler method obtains similar results to the incremental method but never leads to allocations in excess of the required capital in isolation. The method proposed does not provide any diversification benefit to segments perfectly correlated to others, which is an important advantage with respect to other methods.

\section{Discussion}

Solvency II has important implications on the way in which entities should carry out their risk management processes. European companies must have a comprehensive risk management system (ERM) capable of quantifying their risk via all their components. Ref. [29] evidences that more implementation and quality of ERM positively affects the performance of European insurers. Companies should be able to distribute capital charges to those responsible for them in order to make better-informed decisions, i.e., to allocate the capital. In this way, capital allocation to segments or business lines allows the company to maximize its value. If the net income of a business line is greater than its cost of capital multiplied by the capital allocated to it, it contributes to the goal of maximizing value. 
Managers also want the information on the capital of each business line to identify the most and least profitable ones in issues related to risk and setting premiums, for example.

The capital allocation problem is a continuous hot topic in literature with multiple recent proposals techniques, especially for financial institutions (see the recent references [30-36]). An array of capital allocation methods have been explained in the literature, see a summary in $[10,21]$, among others, but many do not correctly address the diversification benefit between business lines. These methods have traditionally been exposed in journals of a mathematical, statistical, or actuarial scope, but they have profound practical economic implications. Diversification means reducing risk by participating in a portfolio of businesses (multi-line insurer) rather than in a single-line company (single-line insurer). The benefits of diversifying a risk portfolio should be assigned in the last instance to the risks that cause the benefits and not benefit segments that do not contribute to diversification. Another problem with the methods analyzed is that, in some cases, they are not coherent methods of capital distribution in that several cause the capital charges assigned to a business line for participating in a risk portfolio to be higher than its capital requirements if it is an independent unit-Denault's first axiom [19]. This article presents a new method, to our knowledge, which is a simple technique in the [10] classification, easy to apply within the Solvency II framework, and assigns the diversification benefit to the contributing LoBs that fulfil the desired characteristics of the capital allocation methods. By way of its practical application, our paper is intended for European companies who need to clear up any doubts about capital allocation, and it can easily be extended to other capital requirements. Unlike other methods not analyzed in this work, it does not require knowledge of volatilities, returns or correlations with assets-see, for example, the Myers and Read method [37] and the CAPM method documented in [9]—or loss distributions of the business lines and the company to be simulated-see the "RMK algorithm" described in [20,21] —or the transformation of the loss distributions of [38].

We propose a new method for allocating capital without private information in a Solvency II context, which is sensitive to correlations between segments and with several desirable properties. Through a practical capital allocation exercise and several sensitivity analyses of the baseline hypotheses we show for some methods analyzed that the capital of an individual segment could be higher than in the case of an isolated segment, i.e., a monoline insurer. Different to other methods analyzed, the technique proposed does not provide any diversification benefit to segments perfectly correlated to others, which we believe is also an important advantage. The limitations of our study come from the fact that the analysis here is based on specific data and do not resolve the companies' problem of choosing the "correct" method. More research is needed to verify whether the proposed new method is suitable to other situations. In addition, the review of the allocation methods has not been exhaustive, so further simulation exercises in which the results of the different methods are evaluated under different circumstances (normality or not, different risk measures, etc.) are required.

Author Contributions: Conceptualization, P.D.-S. and L.O.-G.; methodology, P.D.-S. and L.O.-G.; software, P.D.-S.; validation, L.O.-G.; formal analysis, P.D.-S.; data curation, P.D.-S.; writing-original draft preparation, P.D.-S.; writing-review and editing, L.O.-G.; supervision, L.O.-G.; project administration, P.D.-S.; funding acquisition, P.D.-S. and L.O.-G. All authors have read and agreed to the published version of the manuscript.

Funding: We acknowledge the funding of: the Galician Regional Government [ED431C 2020/18] co-funded by the European Regional Development Fund (ERDF/FEDER) for the period 2020-2023.

Institutional Review Board Statement: Not applicable.

Informed Consent Statement: Not applicable.

Data Availability Statement: Not applicable.

Conflicts of Interest: The authors declare no conflict of interest. 


\section{References}

1. Baione, F.; De Angelis, P.; Granito, I. Capital allocation and RORAC optimization under Solvency 2 standard formula. Ann. Oper. Res. 2021, 299, 747-763. [CrossRef]

2. Durán, P.; Otero, L. Enterprise risk management and Solvency II: The system of governance and the Own Risk and Solvency Assessment. J. Risk Financ. 2020, 21, 317-332. [CrossRef]

3. Dhaene, J.; Tsanakas, A.; Valdez, E.A.; Vanduffel, S. Optimal Capital Allocation Principles. J. Risk Insur. 2012, 79, 1-28. [CrossRef]

4. $\quad$ D'Arcy, S.P. Capital Allocation in the Property-Liability Insurance Industry. Variance 2011, 5, 141-157.

5. Albrecht, P. Risk based capital allocation. In Encyclopaedia of Actuarial Science; Wiley: Chichester, UK, 2006.

6. Balog, D. Capital Allocation in the Insurance Sector. Financ. Econ. Rev. 2017, 16, 74-97. [CrossRef]

7. Balog, D.; Bátyy, T.L.; Csóka, P.; Pintér, M. Properties and comparison of risk capital allocation methods. Eur. J. Oper. Res. 2017, 259, 614-625. [CrossRef]

8. Corrigan, J.; De Decker, J.; Hoshino, T.; van Delft, L.; Verheugen, H. Aggregation of Risks and Allocation of Capital. Milliman. Available online: http:/ / www.milliman.com/uploadedFiles/insight/research/life-rr/aggregation-of-risks-allocation.pdf (accessed on 29 December 2021).

9. Cummins, J.D. Allocation of Capital in the Insurance Industry. Risk Manag. Insur. Rev. 2000, 3, 7-27. [CrossRef]

10. Eling, M.; Schmeiser, H. The Risk Premium Project (RPP) Update-RPP II Report. Technical Report. Casualty Actuarial SocietyCommittee on Theory of Risk. 2010. Available online: https://www.alexandria.unisg.ch/238398/1/Eling\%20Schmeiser\%20 Studie\%202010.pdf (accessed on 29 December 2021).

11. Meyers, G.G. The Economics of Capital Allocation. Casualty Actuarial Society Forum, Fall. 2003, pp. 391-418. Available online: http:/ / citeseerx.ist.psu.edu/viewdoc/download?doi=10.1.1.536.5578\&rep=rep1\&type=pdf (accessed on 29 December 2021).

12. Venter, G.G. Capital Allocation Survey with Commentary. N. Am. Actuar. J. 2004, 8, 96-107. [CrossRef]

13. Venter, G.G. Strategic Planning, Risk Pricing and Firm Value. In Proceedings of the ASTIN Colloquia, Helsinki, Finland, 1-4 June 2009; Available online: https:/ / www.actuaries.org/ASTIN/Colloquia/Helsinki/Papers/S7_22_Venter.pdf (accessed on 29 December 2021).

14. Zhang, Y. Allocation of Capital between Assets and Liabilities. ASTIN Bull. 2008, 28, 1-11. [CrossRef]

15. Guo, Q.; Bauer, D.; Zanjani, G. Capital Allocation Techniques: Review and Comparison. Variance 2021, 14. Available online: https://variancejournal.org/article/29684-capital-allocation-techniques-review-and-comparison (accessed on 29 December 2021).

16. Bodoff, N.M. Capital Allocation by Percentile Layer. Variance 2009, 3, 13-30.

17. Stoughton, N.M.; Zechner, J. Optimal capital allocation using RAROC ${ }^{\mathrm{TM}}$ and EVA ${ }^{\circledR}$. J. Financ. Intermediation 2007, 16, 312-342. [CrossRef]

18. Phillips, R.D.; Cummins, J.D.; Allen, F. Financial Pricing of Insurance in the Multiple-Line Insurance Company. J. Risk Insur. 1998, 65, 597-636. [CrossRef]

19. Gründl, H.; Schmeiser, H. Capital Allocation in Insurance: Economic Capital and the Allocation of the Default Option Value by Michael Sherris and John van der Hoek, April 2006. N. Am. Actuar. J. 2007, 11, 163-165. [CrossRef]

20. Denault, M. Coherent Allocation of Risk Capital. J. Risk 2001, 4, 1-34. [CrossRef]

21. Ruhm, D.; Mango, D. A Method of Implementing Myers-Read Capital Allocation in Simulation. Casualty Actuarial Society Forum, Fall. 2003, pp. 451-458. Available online: https://www.casact.org/sites/default/files/database/forum_03fforum_03ff451.pdf (accessed on 29 December 2021).

22. Kreps, R. Riskiness Leverage Models. Proc. Casualty Actuar. Soc. 2005, 91, 31-60.

23. Homburg, C.; Scherpereel, P. How should the joint capital be allocated for performance measurement? Eur. J. Oper. Res. 2008, 187, 208-217. [CrossRef]

24. Moody's Analytics. Capital Attribution Methods. 2014. Available online: https://www.moodysanalytics.com/-/media/ whitepaper/2014/2014-29-08-research-report-capital-attribution.pdf (accessed on 29 December 2021).

25. Durán, P.; Otero, L.; Martorell, O.; Merigó, J.M. Backtesting an equity risk model under Solvency II. J. Bus. Res. 2018, 89, $216-222$. [CrossRef]

26. Doff, R. The Final Solvency II Framework: Will It Be Effective? Geneva Pap. Risk Insur.-Issues Pract. 2016, 41, 587-607. [CrossRef]

27. Durán, P.; Otero, L.; Martorell, O.; Gil-Lafuente, A.M. Property risk under solvency II: Effects of different unsmoothing techniques. Technol. Econ. Dev. Econ. 2019, 25, 1-19. [CrossRef]

28. Saavedra-Nieves, N. Package 'GameTheoryAllocation'. 2016. Available online: https://cran.r-project.org/web/packages/ GameTheoryAllocation/GameTheoryAllocation.pdf (accessed on 29 December 2021).

29. Otero-González, L.; Durán-Santomil, P.; Marouf, D. Can ERM ratings explain the performance and risk of EMEA insurance companies? J. Risk Res. 2022, in press. [CrossRef]

30. Cai, J.; Wang, Y. Optimal capital allocation principles considering capital shortfall and surplus risks in a hierarchical corporate structure. Insur. Math. Econ. 2021, 100, 329-349. [CrossRef]

31. Urbina, J.; Santolino, M.; Guillen, M. Covariance Principle for Capital Allocation: A Time-Varying Approach. Mathematics 2021, 9 , 2005. [CrossRef]

32. Chong, W.F.; Feng, R.; Jin, L. Holistic principle for risk aggregation and capital allocation. Ann. Oper. Res. 2021, in press. [CrossRef] 
33. Boonen, T.J.; De Waegenaere, A.; Norde, H. A generalization of the Aumann-Shapley value for risk capital allocation problems. Eur. J. Oper. Res. 2020, 282, 277-287. [CrossRef]

34. Asimit, V.; Peng, L.; Wang, R.; Yu, A. An efficient approach to quantile capital allocation and sensitivity analysis. Math. Financ. 2019, 29, 1131-1156. [CrossRef]

35. Kang, W.-Y.; Poshakwale, S. A new approach to optimal capital allocation for RORAC maximization in banks. J. Bank. Financ. 2019, 106, 153-165. [CrossRef]

36. Gzyl, H.; Mayoral, S. A numerical approach to the risk capital allocation problem. J. Risk 2021, 23, 55-78. [CrossRef]

37. Myers, S.C.; Read, J.A., Jr. Capital Allocation for Insurance Companies. J. Risk Insur. 2001, 68, 545-580. [CrossRef]

38. Wang, S.S. A class of distortion operators for pricing financial and insurance risks. J. Risk Insur. 2000, 67, 15-36. [CrossRef] 